\title{
Depiction of gene-environment relationships in online medical recommendations
}

\author{
Youyou Cheng, $M A^{1}$, Celeste Condit, $P h D^{2}$, and David Flannery, $M D^{3}$
}

\begin{abstract}
Purpose: This study examines the presentation of genetic and behavioral causation and prevention in websites that make medical recommendations to lay people for four diseases: heart disease, diabetes, lung lancer, and depression. Methods: A sample of 73 online medical recommendations from major health institutions and information portals were retrieved for content analysis, with a focus on the depiction of gene-environment relationships. Results: The results show a clear preponderance of behavioral causation and recommendations. When genetic information is presented, genetic and environmental factors (including behaviors) are depicted as independent contributors to health outcomes, rather than as interactive. Conclusion: This study suggests that interactive depictions of genes and behavior should be considered when genetics is presented in medical accounts of causation and prevention of common, complex diseases. Genet Med 2008:10(6):450-456.
\end{abstract}

Key Words: gene-environment relationship, gene-environment interaction, online medical recommendation, fatalism, genetic determinism, risk communication, health communication

With the mapping and sequencing of the human genome now complete, both medical geneticists ${ }^{1,2}$ and their critics $^{3,4}$ expect that the practice of public health is likely to become "geneticized" such that information about genetic risks will be more widely available. Many medical geneticists expect that human genome research will reveal information about individual susceptibility to diseases so that people can learn of their risks for future illness, and thereby be enabled to practice more effective health maintenance and disease prevention. ${ }^{2}$ Public health professionals are increasingly using more genetic information to target interventions of behavioral and environmental factors that lead to many diseases. ${ }^{1}$ Given that this dramatic increase in information regarding genetically-induced illness brings with it numerous social, psychological, and ethical challenges, ${ }^{5}$ it is essential, at the least, that such genetic information is conveyed from professionals to lay individuals in an accurate manner. However, communicating about genetic information with the lay public in a fashion to achieve these goals is likely to be challenging.

Researchers have argued that the increasing mass media coverage of genetic research might promote biological deter-

\footnotetext{
From the ${ }^{1}$ Biomedical and Health Sciences Institute; ${ }^{2}$ Department of Speech Communication, University of Georgia, Athens, Georgia; and ${ }^{3}$ Department of Pediatrics, Medical College of Georgia, Augusta, Georgia.

Youyou Cheng, MA, Biomedical and Health Sciences Institute, University of Georgia, N106 Coverdell Center, Athens, GA 30602.E-mail:youyou@uga.edu.

Disclosure: The authors declare no conflict of interest.

A supplementary table is available via the ArticlePlus feature at www.geneticsinmedicine.org. Please go to the June issue and click on the ArticlePlus link posted with article in the Table of Contents to view this material.

Submitted for publication November 21, 2007.

Accepted for publication March 4, 2008.

DOI: 10.1097/GIM.0b013e31817701a8
}

minism, thus leading to negative outcomes such as fatalism, discrimination, and lower likelihood that individuals might adopt preventive health behaviors, ${ }^{3,4,6-11}$ or even lead to poorer health outcomes. ${ }^{12-14}$

Research also suggests that lay people are less likely to believe that a condition caused by "genetics" is amenable to treatment. ${ }^{15,16}$ In an experimental study conducted by Senior et al., ${ }^{17}$ for example, participants were given messages that either attributed a prediction of future heart disease to the outcome of a genetic test or to that of an unspecified test. Those who were told that the results were based on a genetic test saw the disease as less preventable.

The tendency to perceive genetic causation as inconsistent with effective behavioral prevention coexists with a tendency of lay people to understand genes and the set of other factors generally grouped as "environment" to be separate from each other, rather than as interacting. ${ }^{18,19}$ Although the details of how lay people interpret this model of separate causation are not yet clearly documented, for at least some people, seeing genes and behaviors as separate may mean that they believe that when risk-increasing versions of genes are present, genes trump behaviors. This interpretation seems likely for the approximately one-quarter to one-third of the population who hold highly genetically deterministic views of heart disease ${ }^{20}$ and other common conditions. ${ }^{21}$ For such individuals, behavioral changes such as healthier diet or exercise may not be perceived as effective preventative strategies for "genetic" diseases.

As researchers have pointed out, this "separate causation" model is inaccurate. ${ }^{19,22} \mathrm{~A}$ common spectrum of disease causation ranges from completely genetic to completely environmental, and in most cases, the genetic factors and environmental factors interact synergistically. Thus, at one level of 
environmental exposure, allele\#1 may produce a higher level of risk than allele\#2, whereas at another level of environmental exposure, the risk levels may be equivalent or even reversed. As Khoury et al. ${ }^{19}$ point out, the separate causation conceptualization is often evident in the form of a pie chart used to summarize and present information about causes of a specific condition that add up to $100 \% .{ }^{19}$ However, stating that some condition is $60 \%$ genetic and $40 \%$ environmental is simply misleading, because most if not all human diseases result from the interaction between genetic susceptibility and environmental factors. We call the model implicit in the pie chart an "additive" model. The additive model has been replaced in scientific research by the interactive model at the general level, and is in the process of being replaced in concrete characterizations in a wide range of disease-specific research. ${ }^{23-25}$ It is desirable to understand the barriers that seem to be preventing lay people's adoption of these interaction models. The diffusion of innovation mode ${ }^{26}$ suggests that new technologies and knowledge would spread through society with an S-shaped curve. The early adopters ( $10-25 \%$ of the society members) select the innovation first, followed by relatively rapid adoptions by the majority, until it becomes common practice. ${ }^{26}$ Regarding accurate information on gene-environment relationships, medical professionals, researchers, and institutions are the early adopters and lead the way in learning the vast amount of genetic information. They are also likely to be one set of opinion leaders ${ }^{27}$ who have the potential to channel information to the public.

There is empirical evidence that websites have become a key channel for diffusing innovations from medical experts to the lay public. According to data from the Health Information National Trends Survey, ${ }^{28}$ in 2003, 50.7\% of respondents reported looking for health or medical information on the internet for themselves. In 2005, the percentage increased to $58.4 \%$. In $2003,45.8 \%$ of respondents reported looking for health or medical information on the internet for others, and in 2005, $59.5 \%$ of respondents reported so. When asked where they actually went for health information in 2003, 48.6\% indicated they searched online first, with only $10.9 \%$ contacting their physicians first. ${ }^{29}$ Therefore, it is plausible that lay individuals seek and acquire information on genetic information from such websites. Although these are unlikely to be the sole sources of lay understanding of gene-environment relationships, an assessment of the content of these websites should allow us to offer recommendations to these institutions on how to communicate genetic information better, to avoid increasing deterministic or fatalistic beliefs among lay individuals. The goal of this article is therefore to examine the disease prevention discourse addressed to the public on the web by health organizations such as National Institute of Health, Center for Disease Control and Prevention, and WebMD (table available online only), using web content analysis.

The focus of the sample of websites used for this analysis will be disease prevention and treatment, because web site creators seem to assume that lay people go to the web looking for this information, rather than going primarily searching for causal information. However, most of these sites describe causal and risk factors as well as prevention and cure recommendations. Consequently, these are the primary sites that represent causes of disease to lay people. The pairing of causal and prevention information gains support from the developing theories that show a link between lay people's understanding of health causation and their sense of appropriate cures. ${ }^{9,30}$ Preventative or curative prescriptions are in many cases most credible or comprehensible when the prescription is consonant with the lay person's understanding of the cause or mechanism of the disease. ${ }^{15,17,31,32}$ For example, if lack of exercise is perceived as a cause of an illness, more exercise will be perceived as a credible way of getting better. In contrast, if genetics is perceived as a cause of heart disease, then neither exercise nor dietary factors will be perceived as helpful. As a result, genetic risk provision may influence not only causal attributions, but also perceptions of disease preventability and self-efficacy of engaging in preventive health behaviors. ${ }^{17}$

It is effectively impossible to analyze every disease given the variety and complexity of medical conditions. Four diseases thus were selected for this study. Because of the prevalence, seriousness, and potential for prevention of heart disease and diabetes, these two conditions were included in the analysis. Because lung cancer is the leading cause of cancer-related death in the United States ${ }^{33}$ and is widely perceived as a serious disease but under greater volitional control than heart disease and diabetes (because of smoking behavior ${ }^{21}$ ), it was also included to expand the potential range of understandings of gene-environment relationships. It would be desirable to understand the breadth of the range of lay people's understanding of gene-behavior interaction. Given research showing that lay people harbor a "mind-body" dualism that assigns greater causative roles to genetics for conditions perceived as "physical" and lesser for conditions perceived as "mental," 34 it was deemed important to include depression, which is the mental condition that receives the most widespread attention on the web. ${ }^{35,36}$

\section{METHOD}

\section{Retrieval of online recommendations}

Web content analysis will be used as the main methodology for this study. Content analysis uses human coders to assign statements to a set of categories that indicate the themes of interest. It employs intercoder reliability checks to achieve a systematic, objective, and quantitative method for studying the content of communication. ${ }^{37}$ As a form of the new media, the World Wide Web serves similar communication functions as other mass media, but also opens additional realms for content analytic research because of its interactivity, decentralization, and global reach. ${ }^{38}$

A two-step online search was conducted to develop the sample of online medical recommendations. First, links were obtained from the website of the American Public Health Association $^{39}$ with focus on four diseases: heart disease, diabetes, lung cancer, and depression. Second, the investigators also 
used several popular search engines such as Google, MSN, Ask, and Yahoo to find additional websites, using the key words "heart disease prevention," "prevent heart disease," "risk factors of heart disease," "heart disease risks," "causes of heart disease," "heart disease causes." The other three diseases are substituted in the key words to generate relevant results. The links of relevant results from each search engine were retained and their contents were retrieved for analysis. Then the investigators examined the webpage for prevention recommendations, and information about causes and risk factors for diseases. News stories and recommendations from unidentified sources were excluded from the analysis. In total 73 unique messages on 71 webpages from 46 sponsor health institutions, foundations, and companies were retrieved for content analysis. The table available online only presents the links to, and summary of the recommendations. All websites analyzed were saved as webpage complete (. htm) files to a local hard disk and archived in August 2007, so they may be viewed as they appeared when initially accessed. Given that a website changes constantly, this is a crucial step in web content analysis. ${ }^{38}$

\section{Content analysis of medical recommendations}

\section{The coding scheme}

A coding scheme is the set of all coding categories applied to a collection of texts, in which a "coding category" identifies the extant options different messages employ within a particular content domain. ${ }^{40}$ The coding scheme for this study was adapted from a content analytic scheme developed from two interview studies $(n=50, n=46)$ that collected qualitative data on lay perceptions of the roles of genes and the environment in determining health status. ${ }^{41}$ The coding scheme included categories such as disease type (e.g., if the message talks about heart disease versus diabetes versus lung cancer versus depression); message purpose (e.g., prevention or causes/risk factors), and causality (gene versus behavior versus both),. In contrast to machine based coding that uses fixed dictionaries that assign a set of words to each category, the use of human coders enables judgments about the meaning of words in context. It is therefore not possible to specify in advance all of the words included in each category, however, e.g., such key terms as "gene," "genetics," "family history" would in most cases be coded as a focus on genes, whereas notions of "race" based on human genetic variation might also be coded as a gene focus, because lay people tend to interpret race as having a genetic component ${ }^{42}$; whereas such key words as "exercise," "diet," "drinking," "smoking" would generally be coded as an emphasis on the environment.

The text was further coded with regard to the relationship between genes and environment in determining health status: A "behavior only model" attributes one's health condition/ disease to behavioral factors only and/or recommends lifestyle change as preventive measures. A "gene only model" considers only genes as causes and risk factors of health conditions and fails to offer any behavioral recommendations. An "additive model" considers both genes and behaviors as factors that de- termine one's health conditions; however, these two forces are viewed as independent of each other; therefore, their impact on one's health is additive. A "trigger" model is an interactive one, but it is "all or nothing" or in a compressed time span. The genes have no impact on one's health unless they are activated by the effect of a particular behavior or environmental component. The trigger model may also imply a compressed time span such that the disease occurs immediately upon exposure to the "trigger." In what we labeled as the "interactive" model, both genes and behaviors are important factors to one's health; moreover, their impact is synergistic through time, that is, the impact of genes on health varies on different levels of behavior or vice versa. If a recommendation suggests a genetic test or checking for family history, it would generally be coded as genetic risk and the coders would then analyze the gene-environment relationships in the text.

\section{Intercoder reliability}

Following the coding scheme, two coders coded the text for 40 of the 73 recommendations. The intercoder reliability (Krieppendorff $\alpha^{43}$ ) was assessed upon this proportion of the data using the Concord package in the open source software package $R$. Krippendorff $\alpha$ ranged from 0.81 to 1 for all variables. They were all above the minimal requirement of 0.80 suggested by Riffeet al. ${ }^{44}$ Differences between the coders were resolved through discussion. One of the coders then coded the rest of the data.

\section{RESULTS}

\section{Presence of genetic information}

Thirty-eight of the total 73 messages presented genetic information that was denoted by the phrase/word of "gene," "genetics," "family history," "race," or some combination of the three. Direct words such as "gene" or "genetic" appeared mostly in messages about depression, whereas indirect words such as "family history" appeared comparatively often in diabetes messages. Race or ethnicity information appeared mostly in diabetes information as well. Table 1 presents the frequencies of the gene theme across the health conditions of heart disease, diabetes, lung cancer, and depression.

\section{Presence of environmental information}

Behavior regulation (e.g., diet, exercise, drinking, and smoking), social facilitation (e.g., family and friends relationships, and socio-economic status), and physical environment (e.g., air, working conditions, and living surroundings) are regarded as three distinctive types of nongenetic factors which we grouped as global "environment." Each of the web pages features at least one of these three elements of the environment theme. A closer inspection showed that behavioral factors were mentioned in almost all messages (in 72 of the 73 ) and 19 of 73 mentioned social facilitation and 23 mentioned a physical environmental factor (Table 2). Messages about heart disease and diabetes predominantly discuss behavioral factors as the nongenetic component. Social facilitation, however, was much 
Table 1

Presence of genetic information across diseases

\begin{tabular}{|c|c|c|c|c|c|c|}
\hline & \multicolumn{2}{|c|}{ Presence of gene } & \multicolumn{2}{|c|}{ Presence of family history } & \multicolumn{2}{|c|}{ Presence of race } \\
\hline & Count & $\%$ within disease & Count & $\%$ within disease & Count & $\%$ within disease \\
\hline Heart disease & 2 & 11.1 & 8 & 44.4 & 4 & 22.2 \\
\hline Diabetes & 2 & 10.5 & 12 & 63.2 & 9 & 47.4 \\
\hline Lung cancer & 2 & 11.8 & 6 & 35.3 & 1 & 5.9 \\
\hline Depression & 10 & 52.6 & 9 & 47.4 & 0 & 0 \\
\hline Total & 16 & 21.9 & 35 & 47.9 & 14 & 19.2 \\
\hline
\end{tabular}

Table 2

Presence of environmental information across diseases

\begin{tabular}{|c|c|c|c|c|c|c|}
\hline & \multicolumn{2}{|c|}{ Presence of behavioral regulation } & \multicolumn{2}{|c|}{ Presence of social facilitation } & \multicolumn{2}{|c|}{ Presence of physical environment } \\
\hline & Count & $\%$ within disease & Count & $\%$ within disease & Count & $\%$ within disease \\
\hline Heart disease & 18 & 100.0 & 2 & 11.1 & 1 & 5.6 \\
\hline Diabetes & 19 & 100.0 & 0 & 0 & 1 & 5.3 \\
\hline Lung cancer & 17 & 100.0 & 1 & 5.9 & 16 & 94.1 \\
\hline Depression & 18 & 94.7 & 16 & 84.2 & 5 & 26.3 \\
\hline Total & 72 & 98.6 & 19 & 26.0 & 23 & 31.5 \\
\hline
\end{tabular}

more discussed regarding depression compared with other diseases. Environmental factors, in contrast, were mentioned much more in messages dealing with lung cancer compared with other diseases. Whereas for heart disease and diabetes, most messages only discussed one type of nongenetic factor, for lung cancer two types of nongenetic factors were always mentioned (behavior and physical environment); and for depression, two or three types were mentioned (especially behavior and social facilitation).

\section{Co-presence of gene and environment themes}

In 38 of the total 73 messages, both the gene theme and environment theme are present; 35 only mention environment. The gene theme does not appear in any one of the online recommendations by itself. It is always accompanied by some forms of discussion of behavioral factors.

\section{Relationship of gene and environment}

Thirty-five of the total 73 messages depict a behavior only model. These articles focus on the behavior theme only and do not mention genetics at all. An example of such recommendation follows ${ }^{45}$ :

Tobacco use is related to one-third of all cancer and $80 \%$ of all lung cancer. The best way to prevent lung cancer is not to smoke. If you already smoke, you should try to quit. The longer you use tobacco, the greater your risk becomes. Research shows that the chance of developing lung cancer decreases once you quit and continue to abstain from tobacco for a long period of time. You should also avoid breathing in other people's smoke. Nonsmokers ex- posed to secondhand smoke are at an increased risk for developing lung cancer. A nonsmoker living with a smoker has a $25 \%$ increased risk for lung cancer. Never expose children to secondhand smoke. Prolonged exposure can interfere with normal lung development and increase their risk of developing respiratory illnesses such as asthma. In the workplace, follow work and safety guidelines to reduce your exposure to hazardous chemicals and second-hand smoke.

A good diet with lots of fruits and vegetables may also help prevent lung cancer.

Among the thirty-eight messages that contain both the gene theme and the environment theme, 34 present an additive model, in which both genetic and behavioral factors contribute to or add to a person's chance of getting a disease, but there is no indication that these factors interact with each other. This is an example ${ }^{46}$ :

A person with some or all of the following listed health risk factors may never develop type 2 diabetes. However, the latest medical findings show that the chances of getting type 2 diabetes mellitus increase the more health risk factors you have.

- A family history of diabetes. If a parent or sibling in your family has diabetes, your risk of developing type 2 diabetes increases.

- Age over 45. The chance of getting type 2 diabetes increases with age.

- Race or ethnic background. The risk of type 2 diabetes is greater in Hispanics, blacks, Native Americans, and Asians. 
- Metabolic syndrome (also called insulin resistance syndrome).

- Being overweight. If you are overweight, defined as a body mass index $>25$, you are at higher risk of type 2 diabetes.

- Hypertension. High blood pressure increases the risk of developing type 2 diabetes.

- Abnormal cholesterol levels. High density lipoprotein ("good") cholesterol levels under $35 \mathrm{mg} / \mathrm{dL}$ and/or a triglyceride level over $250 \mathrm{mg} / \mathrm{dL}$ increases your risk of type 2 diabetes.

- History of gestational diabetes. Getting diabetes during pregnancy or delivering a baby over nine pounds can increase your risk of type 2 diabetes.

Other health risk factors for type 2 diabetes include:

- A history of polycystic ovary disease.

- Habitually inactive.

- History of vascular disease (such as stroke).

Three messages present a trigger model, where what happens in the external environment and the individual's behaviors activate a gene that predisposes the individual to a higher risk of certain disease. The following is an example of the trigger model $^{47}$ :

There is an increased risk for developing depression when there is a family history of the illness. Not everyone with a genetic predisposition develops depression. Life events, a major loss or change, chronic stress, and alcohol and drug abuse, may trigger episodes of depression.

No messages presented a codable gene-behavior interaction model. Isolated fragments of text might be interpreted by some readers as consistent with an interactive model, such as the

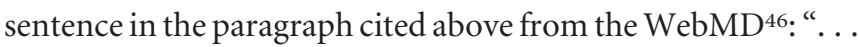
the chances of getting type 2 diabetes mellitus increase the more health risk factors you have." But it is vague and readers could interpret it either as risk factors adding to each other independently, or interacting multiplicatively.

\section{Health conditions and gene-environment relationship}

Table 3 presents the models of gene-environmental relationship within each health condition. Only depression features an interactive model, and it is the "trigger" model. For heart disease, nine recommendations present a behavior only model, nine present an additive model. Interactive models such as trigger or multiplicative are not presented in any of the websites; neither is the gene only model. For diabetes, eight present the behavior only model, 11 present the additive model, and there are no interactive or gene only models presented. For lung cancer, 11 presentations are behavior only model, and the remaining six present the additive model. For depression, seven present the behavior only model, nine represent an additive model, and the remaining three feature a trigger model.
Table 3

Gene-environment relationships across diseases

\begin{tabular}{lccccc}
\hline $\begin{array}{l}\text { Gene-environment } \\
\text { relationship }\end{array}$ & $\begin{array}{c}\text { Heart } \\
\text { disease }\end{array}$ & Diabetes & $\begin{array}{c}\text { Lung } \\
\text { cancer }\end{array}$ & Depression & Total \\
\hline $\begin{array}{l}\text { Additive/platform } \\
\quad \text { Count }\end{array}$ & 9 & 11 & 6 & 8 & 34 \\
$\quad \begin{array}{l}\text { \% of total } \\
\text { Trigger }\end{array}$ & 12.3 & 15.1 & 8.2 & 11.0 & 46.6 \\
$\quad$ Count & 0 & 0 & 0 & 3 & 3 \\
\% of total & 0 & 0 & 0 & 4.1 & 4.1 \\
$\begin{array}{l}\text { Behavior only } \\
\text { Count }\end{array}$ & 9 & 8 & 11 & 8 & 36 \\
$\quad \%$ of total & 12.3 & 11.0 & 15.1 & 11.0 & 49.3 \\
Total & 18 & 19 & 17 & 19 & 73 \\
$\quad$ Count & 24.7 & 26.0 & 23.3 & 26.0 & 100.0 \\
$\quad \%$ of total & & & & & \\
\hline
\end{tabular}

\section{DISCUSSION AND IMPLICATION}

This study examined the websites of major organizations and informational portals that offer health information and recommendations for disease prevention as potentially important sources of information for lay individuals' understanding of genetic and environmental relationships with regard to health outcomes. The content of such online medical recommendations were analyzed for four diseases: heart disease, diabetes, lung lancer, and depression, with focus on genetic and environment information.

Although more than half of the recommendations provided genetic risk information, none of the online sources attribute health status to genes only. In addition, there is a clear dominance of behavioral factors: All the messages mentioned the attribution of environmental factors to human health, including behavior, social, and physical environment. Over $98 \%$ of websites mentioned behavior regulation. When the analysis shifted to how the gene and environment information was presented, the results suggested a strong and potentially undesirable imbalance in representations of gene-environment relationships. Over $82 \%$ of recommendations on sites that discuss genetic information presented an additive model, which considers gene and environment both to contribute to one's health condition, but presents them as working independently, without interaction. Medical recommendation websites thus have not caught up with the evolving science. There are potential reasons for this, including the tendency of websites to feature concrete, disease-specific information, which is still lagging the shift to the interactive model on a more general level.

Nonetheless, as suggested in the introduction, the continued presentation of the additive model might contribute to genetically deterministic or fatalistic thinking when one's genes predispose one to higher risk, instead of lower risk, for a certain health condition, because individuals might assume that the 
genetic component trumps the behavioral factors. Indeed, in on-going analysis of in-depth interviews we have conducted with lay individuals, some people do seem to assume (especially with regard to diabetes, but also heart disease) that behavioral factors only really matter for those who do not have a genetic "cause" to their disease. ${ }^{41}$ The additive approach thus may enhance, for example, perceptions that to the extent that obesity or obesity-related diabetes have genetic components they are not amenable to individual behavioral control or social environmental modification. This is also consistent with French et al. ${ }^{48}$ who found a subadditive model among lay individuals wherein either heavy smoking or a family history of heart disease alone is sufficient for them to perceive high risk.

The trigger model is the only version of an interactive model of the gene-environment relationship that we found in a form fully articulated enough to be codable. It is interesting that this model occurs only in the case of depression. It has previously been identified as occurring in lay discourse about mental health issues (including addiction) ${ }^{34}$ This model is also problematic. It tends to suppress the long-term accretive nature of the impact of most health behaviors. Furthermore, although genes can provide both protection and susceptibility, meaning that they can either decrease or increase one's risks, the trigger model focuses on the negative side. It addresses how one's risk for certain health condition can increase as an outcome of gene and behavior combined, but in the many situations where a behavior cannot be completely avoided (e.g., stress, eating fat, salt, simple sugars), it may not be perceived as providing a model of how one's risks can be reduced and/or disease prevented. In other words, although the trigger model does not provide a model that is genetically deterministic or fatalistic in all cases, it may not facilitate lifestyle change in most cases either. In these cites, more generally, there is an absence of any positive casting of genes as "protective," that is, there are not representations of the concept that some genes may provide some protection for people from some particular health hazards. The most commonly represented models, depicted in opinion leaders on health information, therefore, might be contributing to health fatalism; at least, they have little impact preventing such beliefs.

The analysis also indicates that there is some variation in causal representations according to disease. These variations do not seem to strictly track with a variation in the genetic component or the degree of interaction between genes and other factors in diseases. For example, the documentation of a genetic ${ }^{49}$ and behavioral input exists for lung cancer, but lung cancer is represented predominantly in behavioral terms. In the case of lung cancer, this may be due to the long-standing antismoking campaign's linkage to lung cancer prevention, rather than to the characteristics of disease causation or the developmental stage of the research on interaction effects. More refined attention to the variation in representations by disease seems warranted.

Perhaps the most important finding in the study is a null one-no website presented an accurate and directly articulated representation of gene-environment interaction. Genes and environment interact, which means that the impact of genes on one's health and that of behavior are synergistic. On one hand, some genes can amplify the damages from unhealthy behavior, hence accelerate, or elevate the likelihood of, the occurrence of a certain health condition. On the other hand, this also means that risks can be lowered, among those with genetic risks, once a healthier lifestyle is adopted. Understanding and appreciation of this interactive relationship has the potential to prevent and reverse health fatalism among lay individuals.

This study has not provided an account of all medical recommendations, but only those from a wide variety of frequently visited sites on the web as detailed in the table available online only. The potential effects of the contents as we have described them remain speculative, and additional empirical message effects studies are warranted. Even if studies show that these web sites have the undesirable effects indicated, this does not mean that the web sites have caused the lay attitudes in the historical sense. These web sites may simply be reflecting preexisting lay attitudes. Genetics researchers and medical providers have themselves until recently worked primarily from an additive rather than interactive model. Human language and mental processes may even be biased toward single causation rather than interactive models. ${ }^{50}$ Consequently, it may also be more difficult to communicate the notion of an interaction than an additive model. Whatever the reasons for the existing contents of the websites, efforts to develop effective ways of communicating the somewhat complex notion of gene-behavior interaction to update the representation of genetics on medical recommendation websites seems warranted by a desire for increased accuracy and because it may be important to avoid enhancing genetic determinism and fatalism in the face of an increased presence and role for genetics in public health discourse.

\section{ACKNOWLEDGMENTS}

This research was funded in part by grant NIH 1 R01 HG003961-01.

The first author had full access to all of the data in the study and takes responsibility for the integrity of the data and the accuracy of the data analysis. The authors thank Dr. Lijiang Shen for his valuable suggestions and comments.

\section{References}

1. Centers for Disease Control and Prevention. Translating advances in human genetics into public health action: a strategic plan. Available at: http://www.cdc.gov/ genomics/about/file/print/strategic.pdf. Accessed August 12, 2007.

2. Collins FS, Green ED, Guttmacher AE, Guyer MS. A vision for the future of genomics research. Nature 2003;422:835-847.

3. Hubbard R, Wald E. Exploding the gene myth: how genetic information is produced and manipulated by scientists, physicians, employers, insurance companies, educators and law enforcers. Boston: Beacon, 1993.

4. Nelkin D, Lindee MS. The DNA mystique: the gene as a cultural icon. New York: W. H. Freeman, 1995.

5. Visser A, Bleiker E. Genetic education and counseling. Patient Educ Couns 1997;32: $+1-7$.

6. Chisholm JS, Burbank VK. Evolution and inequality. Int J Epidemiol 2001;30: 206-211.

7. Condit CM. How the public understands genetics; non-deterministic and nondiscriminatory interpretations of the 'blueprint' metaphor. Public Underst Sci 1999; $8: 169-180$. 
8. Cranor CF. Are genes us? The social consequences of the new genetics. New Brunswick: Rutgers University Press, 1994.

9. Hunt K, Davison C, Emslie C, Ford C. Are perceptions of a family history of heart disease related to health-related attitudes and behavior? Health Educ Res 2000;15: 131-143.

10. Hunt K, Emslie C, Watt G. Lay constructions of a family history of heart disease: potential for misunderstandings in the clinical encounter. Lancet 2001;357:11681171 .

11. van Dijck J. Imagination: popular images of genetics. New York: New York University Press, 1998.

12. Garrett JM, Bird SJ. Ethical issues in communicating science. Sci Eng Ethics 2000;6: $435-442$.

13. Fonagy P. The human genome and the representational world: the role of early mother-infant interaction in creating an interpersonal interpretive mechanism. Bull Menninger Clin 2001;65:427-448.

14. Rose S. Moving on from old dichotomies: beyond nature-nurture towards a lifeline perspective. Br J Psychiatry 2001;178:s3-s7.

15. Marteau TM, Senior V. Illness representations after the Human Genome Project: the perceived role of genes in causing illness. In: Petrie KJ, Weinman JA, editors. Perceptions of health and illness. Amsterdam: Harwood Academic Publishers, 1997: 241-266.

16. Senior S, Marteau TM, Peters TJ. Will genetic testing for predisposition for disease result in fatalism? A qualitative study of parents' responses to neonatal screening for family hypercholesterolaemia. Soc Sci Med 1999;48:1857-1860.

17. Senior V, Marteau TM, Weinman J. Impact of genetic testing on causal models of heart disease and arthritis: an analogue study. Psychol Health 2000;14:1077-1088.

18. Walter FM, Emery J, Braithwaite D, Marteau TM. Lay understanding of familial risk of common chronic diseases: a systematic review and synthesis of qualitative research. Ann Fam Med 2004;2:583-594.

19. Khoury MJ, Thrasher JF, Burke W, Gettig EA, et al. Challenges in communicating genetics: a public health approach. Genet Med 2000;2:198-202.

20. Bates BR, Templeton A, Achter PJ, Harris TM, et al. What does 'a gene for heart disease' mean? A focus group study of public understandings of genetic risk factors. Am J Med Genet 2003;119:156-161.

21. Parrott RL, Silk K, Condit CM. Diversity in lay perceptions of the sources of human traits: genes, environments, and personal behaviors. Soc Sci Med 2003;56:1099-1109.

22. Yoon PW, Scheuner MT, Peterson-Oehlke KL, Gwinn M, et al. Can family history be used as a tool for public health and preventive medicine? Genet Med 2002;4:304-310.

23. Hunter DJ. Gene-environment interactions in human diseases. Nat Rev Genet 2005; 6:287-298.

24. Sing CF, Stengard JH, Kardia S. Genes, environment, and cardiovascular disease. Arterioscler Thromb Vasc Biol 2003;23:1190-1196.

25. Phillips C, Lopez-Miranda J, Perez-Jimenez F, McManus R, et al. Genetic and nutrient determinants of the metabolic syndrome. Curr Opin Cardiol 2006;21: 185-193.

26. Rogers EM. Diffusion of innovations, 5th ed. New York: Free Press, 2003.

27. Katz E, Lazarsfeld PF. Personal influence: the part played by people in the flow of mass communications. New York: Free Press, 1955.

28. US Department of Health and Human Services and NIH. Cancer communication health information national trends survey. Available at: http://hints.cancer.gov/ docs/hints_report.pdf.
29. Hesse BW, Nelson DE, Kreps GL, Croyle RT, et al. Trust and sources of health information: the impact of the internet and its implications for health care providers: findings from the first Health Information National Trends Survey. Arch Intern Med 2005;165:2618-2624.

30. Davison C, Frankel S, Smith DG. Inheriting heart trouble: the relevance of commonsense ideas to preventive measures. Health Educ Res 1989;4:329-340.

31. de Valle MN, Norman P. Causal attributions, health locus of control beliefs and lifestyle changes among the pre-operative coronary patients. Psychol Health 1992;7: 201-211.

32. Lau RR, Hartman KA. Common sense representations of common illnesses. Health Psychol 1983;2:167-185.

33. American Cancer Society. Lung cancer. Available at: http://www.cancer.org/downloads/PRO/LungCancer.pdf. Accessed August 3, 2007.

34. Condit CM, Parrott RL, Harris TM. Lay people and behavioral genetics. In: Parens E, Chapman AR, Press N, editors. Wrestling with behavioral genetics: science, ethics, and public conversation. Baltimore: Johns Hopkins University Press, 2006:286-308.

35. Condit CM, Parrott R. Perceived levels of healthy risk associated with linguistic descriptors and type of disease. Sci Commun 2004;26:152-161.

36. Singer E, Corning A, Lamias M. The polls-trends: genetic testing, engineering, and therapy. Public Opin Q 1998;62:633-664.

37. Krippendorff K. Content analysis: an introduction to its methodology. Beverly Hills, CA: Sage, 1980.

38. Weare C, Lin WY. Content analysis of the World Wide Web: opportunities and challenges. Soc Sci Comput Rev 2000;18:272-292.

39. APHA. Public health links. 2007. Available at: http://www.apha.org/about/ Public + Health+Links/. Accessed August 4, 2007.

40. Lewis-Beck M, Bryman A, Liao T. The SAGE encyclopedia of social science research methods. Thousand Oaks: Sage, 2004.

41. Condit CM, Gronnvoll M, Landau J, Shen L, et al. Believing in both genetic determinism and behavioral action: A materialist framework and implications. Public Underst Sci. In press.

42. Condit CM, Parrott RL, Harris TM. Lay understandings of the relationship between race and genetics. Public Underst Sci 2002;11:373-387.

43. Hayes AF, Krippendorff K. Answering the call for a standard reliability measure for coding data. Commun Methods Meas 2007;1:77-89.

44. Riffe D, Fico FG, Lacy S. Analyzing media messages: using quantitative content analysis in research. Mahwah: Lawrence Erlbaum Associates, 1998.

45. Cancer Prevention Foundation. Prevent lung cancer. Available at: http://www.preventcancer.org/healthyliving/cancerinfo/lung.cfm.htm. Accessed August 2, 2007.

46. WebMD. Type 2 diabetes risk factors. Available at: http://diabetes.webmd.com/ guide/risk-diabetes. Accessed August 3, 2007.

47. National Alliance of Mental Illness. What causes major depression? Available at: http: // www.nami.org / Template.cfm?Section=By_Illness\&Template= / TaggedPage / TaggedPageDisplay.cfm\&TPLID $=54 \&$ ContentID = 26414. Accessed August 3, 2007.

48. French DP, Marteau TM, Senior V, Weinman J. Perceptions of multiple risk factors for heart attack. Psychol Rep 2000;87:681-687.

49. Liu G, Wheatley-Price P, Zhou W, Park S, et al. Genetic polymorphisms of MDM2, cumulative cigarette smoking and nonsmall cell lung cancer risk. Int J Cancer 2008; 122:915-918.

50. Pinker S. The stuff of thought: language as a window into human nature. New York: Viking, 2007. 